\title{
Strategic Corporate Social Responsibility, Sustainable Growth, and Energy Policy in China
}

\author{
Lucheng Hong ${ }^{1}$ and Angela Chao ${ }^{2, *}$ \\ 1 School of Electrical Engineering, Southeast University, Nanjing 210096, China; hlc3061@seu.edu.cn \\ 2 School of Management and Economics, Southeast University, Nanjing 210096, China \\ * Correspondence: angela_zc@seu.edu.cn; Tel.: +86-138-158-99407
}

Received: 17 September 2018; Accepted: 31 October 2018; Published: 3 November 2018

\begin{abstract}
China's economy steps into the "new normal" phase, as it is growing in an innovation-driven instead of a factor-driven mode. In this paper, we constructed the corporate behavioral decision models in different scenarios of policy and analyzed the effect of energy policies on corporate behavior and societal welfare, in a duopoly market. The following conclusions were derived. (1) In a duopoly, the product pricing is irrelevant to the resource cost in their production process. (2) For the firm undertaking the social responsibility, the energy tax imposed by the government would increase either the production or the profit, but decrease the consumer surplus. In contrast, for the other firms, the energy tax rate is opposite to their profit. (3) Low-energy-consuming products will promote efficiency, which reduces either the price or the marginal cost, resulting in a more conspicuous cost advantage to the firm adopting the ecological innovation. (4) The marginal cost for a low-energy-consuming technology research and development steadily decreases, which turns their short-term financial disadvantages into the long-term competitive advantages. The marginal contribution of this paper was to build a simultaneously moving model, in duopoly market, and provide theoretical evidence to endogenize the firm strategy to undertake social responsibilities and to realize sustainable growth.
\end{abstract}

Keywords: strategic corporate social responsibility; environmental regulation; energy policy

\section{Introduction}

Sustainability is evolving to become one of the most prominent issues of the global economy, especially in developing countries Isaksson et al. [1]. Corporate sustainability recognizes the importance of growth and profitability of a firm, along with other societal goals Wilson et al. [2]. During the rapid development in the 21st century, China's economy has entered a New Normal stage, which requires both a steady increase in economic growth and a shift from factor-driven to innovation-driven resources and fast wealth accumulate, while the ecological environment keeps deteriorating, as resources are wasted and the environment is polluted. In recent years, the environmental problems in China have been receiving increasing attentions, globally [3]. As major participants in high-speed economic growth, corporations occupy an important part not only in the economy but also in almost every social aspect. The behavior of a corporation is affected by outside factors, like industries, market structures, and policies, and such behaviors, in turn, affect the whole societal welfare, indirectly.

Meanwhile, the concept of consumption changes as environmental conditions deteriorate. Consumers gradually acknowledge the environment-friendly economic models. In this context, corporate social responsibilities (CSR) has been increasingly more prominent within corporations, governments, and consumers [4]. Undoubtedly, corporate nature is the key factor that determines corporate objectives, and the objective is the key factor that determines corporate behaviors. Thus, state-owned corporations exhibit a different CSR behavior than that shown by private corporations $[5,6]$. CSR is the best indicator for commercial morals of an owner or manager of corporations. It deserves to 
be noted that more than half of the corporations in the world disclosed their CSR-related information in the annual financial reports. When making investment, $59 \%$ of the transnational corporations required stakeholders to provide their CSR, for credibility (KPMG, 2013). Corporate Social Responsibility Report of State Grid 2000 was released in Beijing on 16 February 2011, the first CSR Report (CSRR) by a Chinese corporation in the 12th Five-Year Plan. Then, increasing number of key state-owned corporations voluntarily released their CSRR's as an important channel to disclose their CSR information. By the end of 2013, 98.3\% (114 out of 116) of state-owned corporations had released their CSRR. On the one hand, the consumer has a greater initiative in experiencing the economy, hence, the corporation has to pay more attention to its reputation. On the other hand, it is also possible to reduce the burden on the environment by guiding the micro-decision of the corporation through a mechanism design of the government.

There seemed to be a conflicting view on the relationship between the CSR and the corporate financial performance. Neo-classical economics regards the corporation as perfectly rational, who will pursue a maximum profit with scarce resources. Regarding the effect of these theories, there have been producing controversial and paradoxical results Friedman et al. [7]; Freeman et al. [8]; Carroll et al. $[9,10]$. From previous research works done in the field, it was found that corporate objectives for profit and social responsibilities show an internal tension in the corporation, i.e., the two are powers of opposite directions but support each other. However, corporations should be substantially involved in CSR. Additionally, the conception of CSR is limited, where CSR is simply considered as participation in charity activities and a component of a necessary cost but the long-term strategic advantage brought along by CSR is ignored, so corporations cannot endogenize CSR, according to these scholars' theory. In contrast, Carroll, highlighting a different viewpoint, brought stakeholders into the CSR frame, proposing a new conception frame of CSR. Wang and Juslin [11,12] established a theoretical model to measure how a firm's CSR is influenced by human values. It also tests to what extent the consumers' perceptions of CSR act as a predictor of the perceptions of CSR. Porter and Kramer [13] systematically analyzed the relationship between competitive advantages and CSR, and illustrated how corporations made competitive strategies to find chances to realize CSR and attain long-term competitive advantages. Liu et al. [14] pointed out corporations can achieve certificates from an NGO (Non-Government Organization) which encourages them to take Environmental Corporate Social Responsibilities (ECSR). The certificate standard is higher in the Cournot Duopoly than in the Bertrand Duopoly model, and more importantly, corporations and consumers can both reap from the profit of ECSR. However, others believe that CSR activities lead to a lower production and profit. Porter and Kramer attribute this to the fact that corporations regard social responsibilities only as a part of cost but not of strategic policies [13]. Especially in the buyers' market, the consumer preference will be included in the corporations' objective function. Thus, if the corporation's strategic policies are altruistic or consumers-beneficial, we can view CSR as a managerial policy and potentially analyze its economic efficiency.

A survey of the academic literature, which is huge and mostly empirical, is eschewed here. As there is a relationship among CSR, environment, and policy, some literatures researched whether or not corporations took up ECSR in a differential duopolistic market. Through building a game theoretical model, they analyzed various three-stage static games with price competition and quantity competition, in Duopoly. They looked at the process through which oligopolies made profit, its benefits for the whole society, and illustrated how the corporations' social responsibilities affected the environment [15]. Corporations that initially get involved in ECSR have more advantages and are more likely to win more profit in the price competition, which in turn reinforces the corporations' willingness to take on ECSR. Through a two-stage game, Kosuke Hirose (2006) demonstrated that although corporations' that take up ECSR would eliminate the negative externality and increase the wellbeing for the whole society, they would also lose a consumer surplus. Through analysis on corporate, operational, and financial data, Abraham Lioui et al. [16] looked into the relationship between ECSR and corporate financial performance, clarifying the direct and indirect impact of the 
former on the latter. The impact was conspicuously positive if the corporations took up ECSR and invested in green innovations, at the same time. However, the CSR's vary as the market structures vary. With regards to the problem of how corporations take up CSR in a duopoly market, research on the relationship between the environment and the CSR, concludes that it depends on the implications of ECSR, the effect on firm performance, consumer surplus and societal welfare $[17,18]$. Most studies agree that ECSR will promote an overall societal welfare and improve the environment. Li [19] constructed an equilibrium analysis model for CSR in different market structures, offering a more comprehensive explanation.

As Milton Friedman said, CSR is conservative by nature, and he believed that corporations and society are separated and could only be connected through responsibilities [7]. This paper first discusses the following questions through theoretical and empirical research. These include questions such as, what a corporation pursues is not merely for profit but also for the consumers' recognition, then, should CSR be categorized as a part of cost or strategies? Will CSR affect corporate welfare, and if so, what is the mechanism? If a firm focuses on a broader social objective and includes green innovation and CSR as inborn factors of decision behaviors, will this bring a "win-win" for the business, as well as the environment? We also argue that the firm that wins the market, maximizing both consumer surplus and societal welfare, is by no means a zero-sum game. In this paper, combining the CSR, the environmental problems, and the industrial policytogether, has been regarded to be a growing trend for dealing with firm growth and competition. It is far more than necessary to design a model to quantize this trilateral relationship. A marginal contribution of this paper is an attempt to build a CSR-based duopolistic model, and provide theoretical evidence for corporations to endogenize the micro-behaviors of CSR and R\&D, to take up social responsibilities and to realize sustainable growth.

In general, the literature provided numerous perspectives on sustainable energy and ECSR. However these studies are mainly concerned the impacts of firm behavior on environment regulations in a mixed oligopoly $[20,21]$. Nowadays, with the rapid development of economy, the ecological environment is deteriorating, and a sustainable development calls for the innovation of green technology [22]. The firm that anticipates the environmentally-sound technology, gain consumers that are willing to pay a higher price for their products.

In this paper, we explore an important external governance characteristic, which is necessary to focus on the firms' motivation for adopting CSR, in different scenarios of energy policy. So, we define the strategic CSR behaviors, such as eco-R\&D and green technology management, as environmental CSR, conducted to improve reputation.

The detailed dECSRiption of the research model, as well as propositions, are given in Section 2. The simulation results of the consumer surplus, the firm performance, and the societal welfare are showed in Section 3. Section 4 focuses on the main finds and a comparison between the obtained results and the existing studies. Then, the conclusions of this paper, as well as the relevant implications, are delivered in Section 5.

\section{Materials and Methods}

Without doubt, most of the energy sector comprises enterprises that provides crude oil producers, coal, oil-well equipment machinery, gas pipelines, electricity, gas distribution, and water, which stand for the state-owned enterprises, lying upstream in the industrial value-chain, in China. Moreover, it is obvious that there is a trade-off between the consumer surplus and environmental damage, in generating societal welfare, in the polluting industry. In line with previous research (Manasakis et al., 2013, 2014 [23,24]; Chih Liu, 2015 [14]), we expect that socially responsible firms are able to improve not only its performance but also its consumer surplus, in the long-term. Therefore, instead of modeling CSR as a variable cost of the firm's production, we perceive it as an R\&D investment. A three-stage simultaneous-move game has been constructed, consisting of the economic agent, the government, and the firms, which produce the homogeneous productions in the duopoly market. The game is given by the following aspects. In the first stage, the government chooses the degree of energy tax, to maximize 
the societal welfare. In the second stage, the firms choose the strategy of whether or not to undertake CSR. In the last stage, each firm chooses its outputs to maximize the objective function. Backward induction is utilized to derive the sub-game perfect Nash equilibrium. Finally, four critical propositions for analysis are put forward, according to the game model and proofs are provided, respectively.

The steps of the modeling method, in this research, can be considered to be a duopolistic market, where Firm 1 and Firm 2 produce homogeneous productions, as seen in Figure 1.

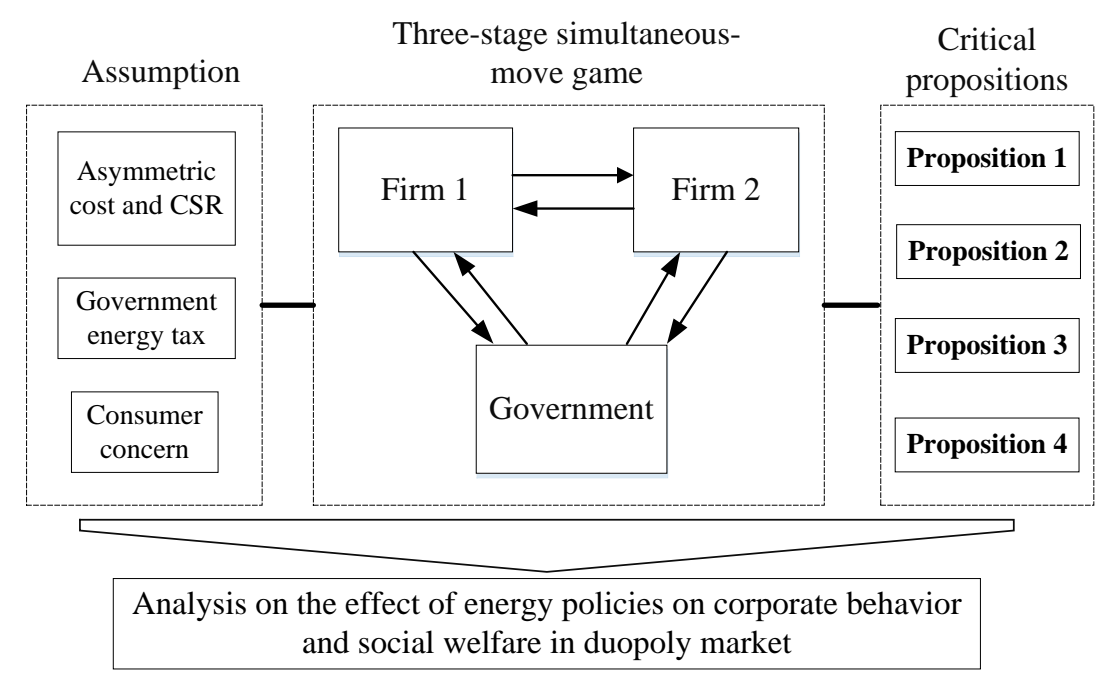

Figure 1. Flowchart of the modeling method.

\subsection{Assumptions}

We adopted a standard homogeneous duopoly model, with a linear demand, in which Firm 1 and Firm 2 produce homogeneous productions. The inverse demand function is given by $P_{i}=1-q_{1}-q_{2}$ $(i=1,2)$, where $P_{i}, q_{i}$ are Firm 1's price and quantity, respectively. The following assumptions are given in Duopoly.

(1) We assumed that Firm 1 is able to invest in a cost-reducing R\&D (eco-R\&D), and provides production $q_{1}$ at price $P_{1}$ while Firm 2 adopts a high-energy-efficiency technique and provides the production $q_{2}$ at price $P_{2}$. Since the technique's cost for improving the energy efficiency is a strict increasing function, in terms of the increment extent of the energy efficiency, Firm 2 has to bear a higher cost than Firm 1, i.e., $C_{1}<C_{2}$.

(2) Suppose government affects the behavior and performance of the corporation by regulating the energy taxes with the ratio of $H(e)$. A higher $H(e)$ means more energy can be consumed. When $H(e)$ $=0$, the energy tax will be imposed at a fixed rate $t$, where the base is the total corporate energy consumption; when $H(e)=1$, no energy tax will be imposed.

(3) Consumers are concerned about the firm's behavior. In other words, consumers can make choices according to their preference, that is, the environmental effect by its production is involved in the consumers' utility function. Additionally, consumers will also pay attention to the corporate reputation. When the lower-energy-consuming products have a price close to that of the normal products, consumers prefer lower-energy-consuming products. With regards to this, assume the environment-friendly index as $\rho$, measuring the product's pollution extent on environment. When the environment-friendly index $\rho$ increases, the product's marginal cost decreases and the ratio of decrease is $\varphi, \rho \in\left(\rho_{0}, \rho_{\mathrm{n}}\right)$. Additionally, the index distribution follows a lack-of-memory pattern. In other words, the pollution extent is independent of the utilization period of a technique. 


\subsection{Theoretical Model}

Consider the simultaneous mover model in duopoly, in which all firms produce homogeneous productions with different energy efficiencies, then obtaining the Cournot equilibrium performance is the ideal result to the duopoly firms and follows the exponential distribution.

$$
f(\rho)=\lambda e^{-\lambda \rho}
$$

$\lambda$ is the improvement index of low-energy efficiency, $e$ is the energy consumption to produce a common product. The relationship between product prices of Firm 1 and Firm 2 is dECSRibed as:

$$
P_{2} \leq P_{1}+L\left(\rho-\rho_{0}\right)
$$

where $L$ is the stepwise difference in price for low-energy product, indicating that with every one unit decrease in energy consumption, the final product price will increase by $L . P_{1}$ and $P_{2}$ are the price of Firm 1 and Firm 2, respectively. Environment-friendly index denotes $\rho$, this parameter also quantitatively rates the consumers' preference of low-energy-consuming (LEC) products. On the contrary, consumers will purchase common products. With prices' variance, the critical point in the consumers' preference for environment-friendly products is given by $\rho^{*}=\frac{P_{2}-P_{1}}{L}+\rho_{0}$, which is the turning point for the consumers' preference. With a purchase of Firm 1's products, the consumer surplus is given by:

$$
C S_{1}=\int_{\rho_{0}}^{\rho^{*}}\left[L\left(\rho-\rho_{0}\right)-P_{1}\right] \lambda e^{-\lambda \rho} d \rho=\left(2 P_{1}-P_{2}\right) e^{-\lambda\left(\frac{P_{2}-P_{1}}{L}+\rho_{0}\right)}-P_{1} e^{-\lambda \rho_{0}}
$$

Similarly, with a purchase of Firm 2's products, the consumer surplus is given by:

$$
C S_{2}=\int_{\rho^{*}}^{\rho_{n}}\left[L\left(\rho-\rho_{0}\right)-P_{2}\right] \lambda e^{-\lambda \rho} d \rho=\left(P_{2}-L \rho_{n}+L \rho_{0}\right) e^{-\lambda \rho_{n}}-P_{1} e^{-\lambda\left(\frac{P_{2}-P_{1}}{L}+\rho_{0}\right)}
$$

The demand for common products is $q_{1}$,

$$
q_{1}=N \cdot \int_{\rho_{0}}^{\rho^{*}} \lambda e^{-\lambda \rho} d \rho=N e^{-\lambda \rho_{0}}\left[1-e^{-\frac{\lambda}{L}\left(P_{2}-P_{1}\right)}\right]
$$

The demand for LEC products is $q_{2}=N-q_{1}$

$$
q_{2}=N-N \cdot \int_{\rho_{0}}^{\rho^{*}} \lambda e^{-\lambda \rho} d \rho=N\left\{1-e^{-\lambda \rho_{0}}+e^{-\left[\lambda \rho_{0}+\frac{\lambda}{L}\left(P_{2}-P_{1}\right)\right]}\right\}
$$

where, $N$ is the fixed market quota, $q_{1}$ and $q_{2}$ are the output of Firm 1 and Firm 2, respectively.

Thus, the objective functions for the two firms are given below, respectively,

$$
\begin{gathered}
\pi_{1}=\left(P_{1}-C_{1}\right) q_{1}-(1-H(e)) e_{1} q_{1} t \\
\pi_{2}=\left[P_{2}-C_{2}+\varphi\left(\rho-\rho_{0}\right)\right] q_{2}-(1-H(e)) e_{1} q_{2} t(1-\mu)-\frac{1}{2} \beta \mu^{2}
\end{gathered}
$$

Each firm optimizes its objective function with respect to $P_{1}$ and $P_{2}$, respectively, and the following first-order conditions are as follows: 


$$
\begin{gathered}
P_{1}{ }^{*}=\frac{2 L}{\lambda}+C_{1}+e_{1} t(1-H(e)) \\
P_{2}{ }^{*}=1-e^{\lambda \rho_{0}}+\frac{L}{\lambda}+C_{2}-\varphi\left(\rho-\rho_{0}\right)+(1-H(e)) e_{1} t(1-\mu)
\end{gathered}
$$

The objective function of the government is maximum societal welfare, formulating the market access threshold to LEC techniques and tax rates of energy tax. Then societal welfare is defined as:

$$
S W=\sum_{i=1,2} C S+\sum_{i=1,2} \pi_{i}+(1-H(e)) e_{1} q_{1} t+(1-H(e)) e_{2} q_{2} t
$$

where $\pi_{1}$ represents the profit of the duopoly firms.

In this way, the three-stage simultaneous-move game has been constructed. Deducing the first derivatives to $C_{2}$ and $C_{1}$ in Equations (9) and (10), respectively:

$$
\frac{\partial P_{1}^{*}}{\partial C_{2}}=\frac{\partial P_{2}^{*}}{\partial C_{1}}=0
$$

Deducing the first derivatives to $\lambda$ in Equations (9) and (10), respectively,

$$
\begin{aligned}
& \frac{\partial P_{1}{ }^{*}}{\partial \lambda}=-2 L \cdot \frac{1}{\lambda^{2}}<0 \\
& \frac{\partial P_{2}{ }^{*}}{\partial \lambda}=-L \cdot \frac{1}{\lambda^{2}}<0
\end{aligned}
$$

According to Equations (13) and (14), as the low-energy efficiency index $\lambda$ increases, the product prices of both Corporation 1 and Corporation 2 decrease. And as $\lambda$ increases, the marginal cost of the corporation's products decreases increasingly faster, which leads to a lower price and advantage gain in the corporation's prices. Additionally, due to $\left|\frac{\partial P_{1}{ }^{*}}{\partial \lambda}\right|>\left|\frac{\partial P_{2}{ }^{*}}{\partial \lambda}\right|, P_{1}$ decreases more conspicuously than $P_{2}$, which means Corporation 1 is more inclined to change to the LEC technique.

Deducing the first derivatives to $t$ in Equations (9) and (10), respectively,

$$
\begin{gathered}
\frac{\partial P_{1}^{*}}{\partial t}=e_{1}(1-H(e))>0 \\
\frac{\partial P_{2}{ }^{*}}{\partial t}=e_{1}(1-H(e))(1-\mu)>0
\end{gathered}
$$

According to Equations (15) and (16), as the energy tax rate $t$ increases, both, prices of the LEC products and the common products, go higher. If the government sets the tax rate appropriately, too high a price can be avoided which will lead to a reduced consumer purchasing power and unmarketable products. Thus, the appropriate tax rate can promote oligopolies to apply LEC techniques.

Based on the above analysis, we put forward the following propositions:

Proposition 1. In a Duopoly, the price of one firm is independent of the resource cost of the other.

The resource cost of each product is related to the pricing. The technique factor in production mainly determines whether the products are LEC and whether the price is high. Thus, the product price of each duopolistic corporation is independent of the resource cost of the other corporation.

Proposition 2. As efficiency is improved, the price and the marginal cost decreases faster.

Given the conditions in Proposition 2, it is very simple to construct examples. If one firm adopts eco-R\&D, then the varying marginal cost will reduce, obviously. In this case, the corresponding firm decreases the price, consequently, but the profit will not be damaged because of the willingness of 
consumers to pay for low-energy-consuming. We can set this to one, by assumption, which allows us to relate the willingness to pay to the cost of the CSR and the maximum willingness to pay for the CSR good, relative to the willingness to pay for the normalized LEC.

Proposition 3. If the energy tax increases, both prices of LEC and the common product will rise.

This conclusion is consistent with the view of ML Song et al. [25], in which they debated on the correlativity among environmental efficiency and particulate matter efficiency, to research the state of energy consumption.

Proof. Both $H(e)$ and $\mu$ are less than 1 . As the slope of the indifference curve equals to that of the budget curve, and the marginal rate of substitution $\left(M R S_{21}\right)$ equals to the absolute value of the slope of the indifference curve and the budget curve, Equation (17) can be deduced from the equilibrium point.

$$
M R S_{21}=\frac{P_{2}}{P_{1}}=-\frac{\Delta X_{1}}{\Delta X_{2}}
$$

Assume $\Delta L$ is the increment in the stepwise price. So, if the other variables remain constant, the increment in $P_{1}$ is $\frac{2 \Delta L}{\lambda}$, and the increment in $P_{2}$ is $\frac{\Delta L}{\lambda} . P_{2}$ has a slower increase rate than $P_{1}$, which means that the LEC product has a lower price than before and substitution is about to take place, while the consumers' utility is not impaired.

Gradually, with the government's encouragement and promotion of energy policies, consumers' growing consciousness of energy consumption, and the steady increase in the relative price of the common products, the common product of Firm 1 will lose it price advantage, eventually, and the LEC products will seize the market completely. Consequently, the following proposition is given:

Proposition 4. As the product's LEC stepwise price L goes higher, prices of both the common product and the LEC product will go higher, but the increment in the LEC product will be much slower, that is, the LEC product incurs a smaller effect. Now let's determine each game player's profit.

Proof. Put $P_{1}{ }^{*}$ and $P_{2}{ }^{*}$ into Equations (5)-(8) and we can have the optimal productions $q_{1}{ }^{*}$ and $q_{2}{ }^{*}$ and the optimal profits $\pi_{1}{ }^{*}$ and $\pi_{2}{ }^{*}$, Let

$$
e^{-\frac{\lambda}{L}\left(P_{2}{ }^{*}-P_{2}{ }^{*}\right)}=\exp \left\{-\frac{\lambda}{L}\left[1-e^{\lambda p_{0}}-\frac{L}{\lambda}+C_{2}-C_{1}-\varphi\left(\rho-\rho_{0}\right)-\mu e_{1} t(1-H(e))\right]\right\}=M
$$

Then, the optimal productions are given, respectively, by

$$
\left\{\begin{array}{c}
q_{1}^{*}=N e^{-\lambda \rho_{0}}(1-M) \\
q_{2}{ }^{*}=N\left(1-e^{-\lambda \rho_{0}}+M e^{-\lambda \rho_{0}}\right)
\end{array}\right.
$$

The optimal profits of the two firms are given, respectively, by

$$
\left\{\begin{array}{c}
\pi_{1}{ }^{*}=N e^{-\lambda \rho_{0}}(1-M) \\
\pi_{2}{ }^{*}=N\left(1-e^{-\lambda \rho_{0}}+M e^{-\lambda \rho_{0}}\right)\left(1+\frac{L}{\lambda}-e^{\lambda \rho_{0}}\right)-\frac{1}{2} \beta \mu^{2}
\end{array}\right.
$$

In conclusion, when energy policies are given, the price is only positively correlated with resource cost but has nothing to do with competitors. If the firm chooses to take partial CSR by voluntarily investing in $R \& D$ for improvement of techniques to decrease its energy consumption, the energy efficiency will increase. The increased efficiency of energy utilization is positively proportional to the decline in the marginal cost of the LEC products. In other words, the firm behavior has a positive effect 
on its profit, in the long-term. If the government imposes the energy tax, the product price goes higher, no matter whether the firm takes up CSR or not. It also means that when the government imposes the energy tax, the consumer surplus decreases, and the producer surplus decreases, as well, in the long term. The government can control product prices and productions by adjusting the rate of the energy tax. Additionally, when the government implements the energy policies, the total productions decrease; and the whole society's energy consumption decreases, which eventually improves the environment, since duopoly firms then take up a partial CSR.

\section{Results}

The following assumptions were made, in order to simplify the model: (1) The government imposes the energy tax at a fixed rate, so we set $H(e)=0$. (2) The environment-friendliness index of the common product and the LEC product are $\rho_{0}=0.2, \rho=0.5$, respectively. (3) The stepwise difference of the LEC product is $L=1$. (4) The energy consumed to produce common products is $e_{1}=1$, the energy decrease rate per unit product is given by $\mu=0.5$, the decrease rate of the product cost is $\varphi=$ 0.1 , the R\&D coefficient is $\beta=1, \lambda=1$, and the energy tax rate $t$ lies in $(0,1)$, with an interval of 0.0001 . The results of the simulation were derived using MATLAB.

\subsection{Consumer Surplus and Energy Policy}

Equations (3) and (4) were simulated by the preset parameters. As shown in Figure 2, when purchasing LEC products, consumers have a significantly lower consumer surplus than when purchasing common products. However, as consumers have to pay more to get the same amount of Firm 2's LEC products, the consumer surplus is not sufficient enough for the LEC products to improve the environment. When the energy tax rate increases, the consumer surplus for purchasing the LEC products increases and vice versa. When the tax rate is increased, Firm 1 voluntarily chooses to undertake CSR, which reduces the energy consumption, increases the environment-friendliness, expand its market, and then eventually leads to a higher consumer surplus. Meanwhile, Firm 2, which produces LEC products, will undertake a partial CSR. The imposition of the energy tax will only increase its product price but not change the product's environment-friendliness index, which leads to a decrease in the consumer surplus. Based on this, when stipulating the energy policies, the government should set an appropriate tax rate to direct corporations to take up CSR, without impairing the consumer surplus.

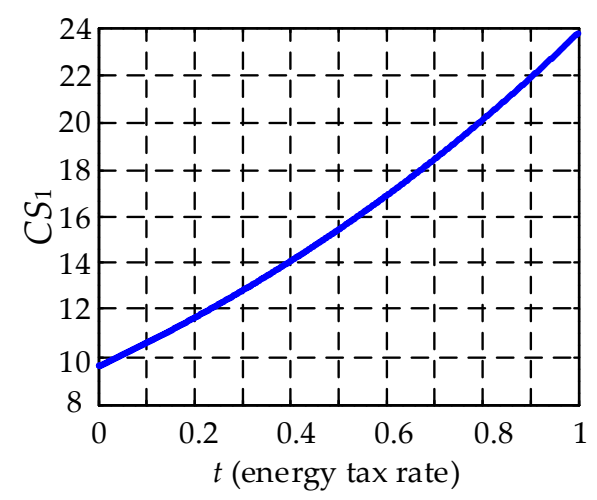

(a)

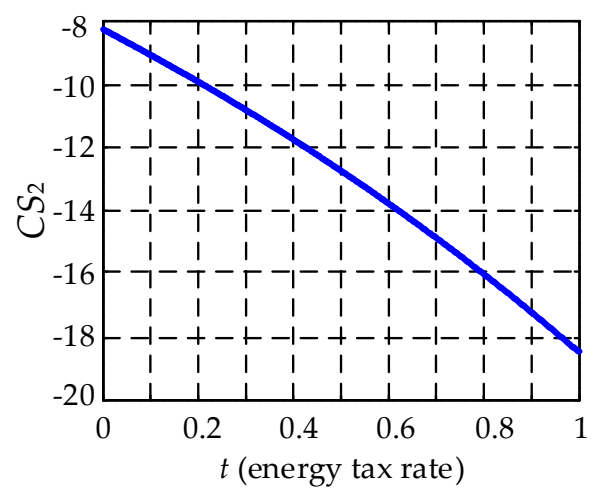

(b)

Figure 2. Simulation results of CS: (a) CS of Firm 1 vs. the energy tax rate; (b) CS of Firm 2 vs. the energy tax rate.

\subsection{Firm Performance and Energy Policy}

According to the previous conditions, we ran a simulation of the third stage, using Equations (5) and (6), and determined the rate of production, with the different tax rates $t$. The simulation result is 
shown in Figure 3. We find that, (1) with the preset parameters and the optimal price, the production of common products of Firm 1 decreases when $t$ increases, that is, Firm 1 lost its price advantage and its production decreases. In contrast, the LEC production of Firm 2 increases when the energy tax is imposed, that is, the energy tax will lead to a higher price of common products and, thus, a higher competition ability of the LEC products. Consequently, the production of Firm 2 would increase, if $t$ increased. The decision of optimal prices and productions, in the energy policy, would be considered first. From Figure 3, the energy tax could promote a higher production rate of the LEC products, and the average environment-friendliness index of the society would increase, which means that the energy policies can substantially improve the environment.

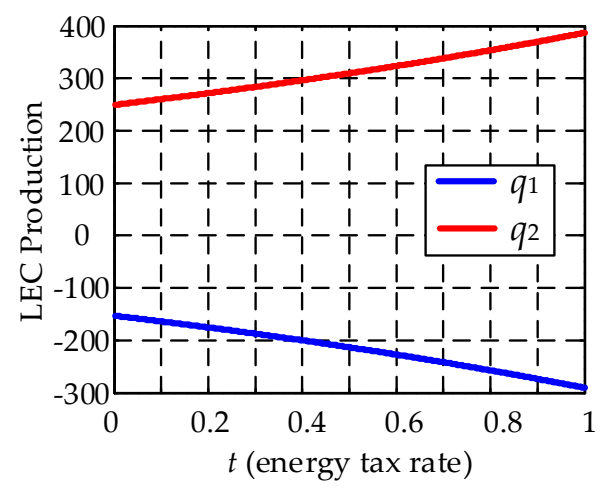

Figure 3. Productions vs. the energy tax rate.

Obviously, the profit of duopoly firms would be influenced by the industrial policies, such as that of the energy tax rate. Equations (7) and (8) were simulated; the results are shown in Figure 4. If Firm 1 does not take CSR and consumes more energy, more energy tax will be levied, which leads to a higher price, a lower production, and consequently a decreased total profit. Meanwhile, the profit of Firm 2 increases as the energy tax rate increases, since the energy tax makes the price of a common product rises at a higher speed than that of the LEC product. Thus, as the energy tax rate increases, Firm 2 can reap a bigger share and a higher profit. Comparing the profits between the duopoly firms in this paper, the energy tax encourages the LEC corporations and beats the high-energy-consuming corporations. With an increased energy tax rate, the cost of the corporation that did not take up CSR, will become increasingly higher. Meanwhile, from the perspective of the profit-change trend of the firm, the LEC Firm 2 reaps a higher profit, with an increased energy tax rate $t$. Hereby, the energy tax rate will direct corporations to undertake CSR and reduce its energy consumption.

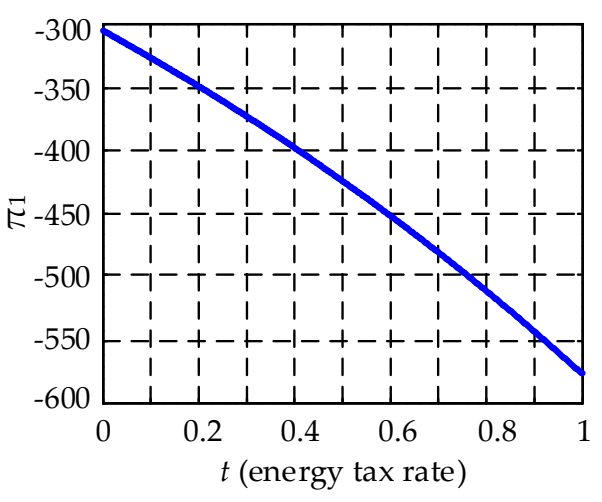

(a)

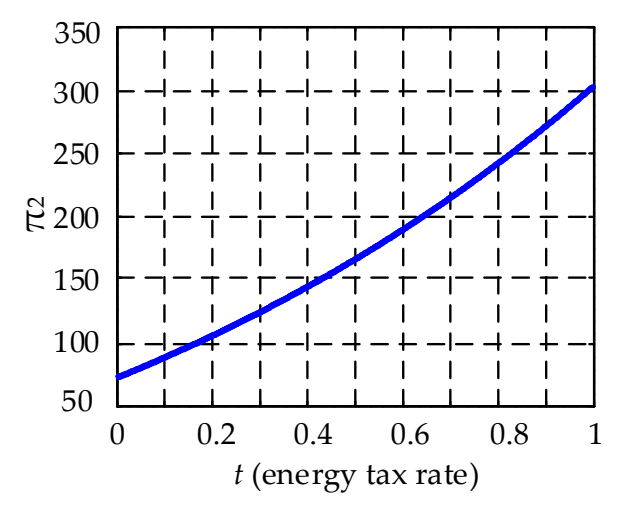

(b)

Figure 4. Simulation results of profit: (a) Profit of Firm 1 vs. the energy tax rate; (b) profit of Firm 2 vs. the energy tax rate. 


\subsection{Social Welfare and Energy Policy}

In the third stage, the government determines the societal welfare through the energy policies. Equation (11) was simulated, and the result is shown in Figure 5. Social welfare increases with a higher tax rate $t$, where the production of Firm 1 decreases, the production of Firm 2 increases, and the consumer surplus decreases. Simultaneously, profit of Firm 1 increases but that of Firm 2 becomes higher, and the tax revenue has a positive inclination. Generally, the societal welfare increases. When more LEC products are provided in the market, the energy tax will not only increase the societal welfare, but will also restrain pollution and improve the environment. However, the energy tax will cause the consumer surplus to decrease, in the short term, so when stipulating the tax rate, the government should consider the substitution effect of the energy policy.

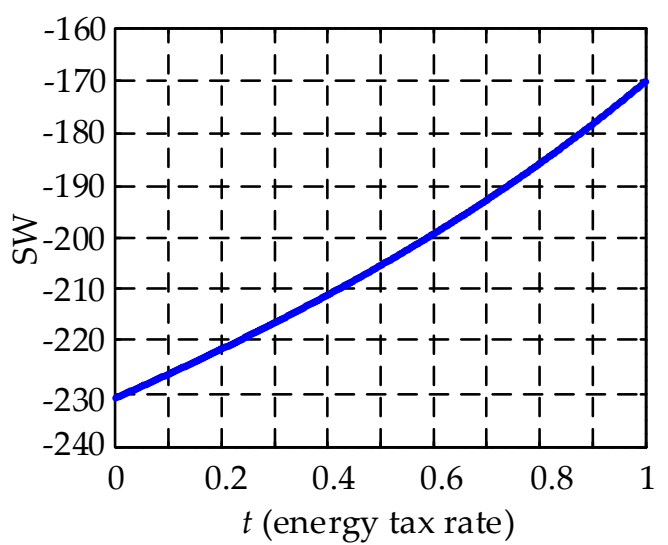

Figure 5. Social welfare vs. the energy tax rate.

Our analysis relies on the assumption that profit-seeking firms have incentives to take on CSR by adopting an eco-R\&D. The perspectives on CSR have evolved, from whether CSR should exist to why it does exist, and how it affects the economy. In comparison with previous studies, we have developed a theoretical model by means of a fixed-rate of energy tax, differential energy decrease rate, and the environment-friendliness index. If more LEC products are provided in the market, the energy tax will not only increase the societal welfare, but will also restrain pollution and improve the environment, though in the short term, a consumer surplus will be damaged. Meanwhile the profit-seeking firm would be better-off to undertake CSR voluntarily to reduce energy consumption and improve the environment-friendliness, in the market, when the government enhances the tax rate. Based on this, when stipulating energy policies, the government should set an appropriate tax rate to direct corporations to take CSR, without impairing the consumer surplus.

\section{Discussion}

To the best of our knowledge, previous studies on strategic CSR have not yet tackled CSR as a device for an incumbent to respond to industrial policy. Moreover, they have assumed that the objective of public firm would not profit seeking with symmetric cost. This paper investigated an asymmetric, profit-maximizing objective, between to firms, to check whether the incumbent firm has an incentive to adopt cost-reducing R\&D activities, as a response to corporate social responsibility. This paper proved that the price of one firm is independent of the resource cost of the other, in a duopoly market. As the efficiency improves as a result of an eco-R\&D, the price and the marginal cost decreases, drastically. If the energy tax increases, both, prices of the LEC and the common product rises, eventually. This is consistent with previous research and reports that state the current status of CSR awareness in Asia.

In this paper, given a policy scenario, such as an adjustable energy tax, we argued for the impacts of a firm's behavior, regarding societal welfare, on the firms' incentive to undertake the "doing well 
by doing good" strategy, as suggested by Baron [26,27]. Specifically, we extended the three-stage simultaneous game in which firms commit to undertake consumer-friendly actions, in the form of an eco-R\&D, in the second stage, and make their quantity decisions, in the last stage. On the basis of this, we also put forward policy recommendations for formulating an energy policy and guiding enterprises to undertake corporate social responsibility. Be'nabou et al. [28] gives an overview of the recent developments in the economics of prosocial behavior and links it to CSR. Lambertini \& Tampieri [29] also construct a static duopoly game, considering firms can choose between profit-seeking or CSR, and their emphasis was on characterizing a mixed-outcome (one, profit seeking and the other, CSR), which is stable for a low impact of pollution and CSR sensitivity.

\section{Conclusions}

As is well-known, CSR is a form of corporate self-regulation. CSR is a strategic and profitable response to entry, in the long term. This paper investigated the incentives of firms for undertaking strategic CSR activities, under quantity competition. We define as CSR firm as one that not only takes into account its profit but is also sensitive to societal welfare. Due to the trade-off between societal welfare and environmental damage, the government have to applicate industrial regulations, such as different energy tax of subsidy, to encourage the firm to take CSR voluntarily.

In this paper, we proposed the reactions of oligopoly in different scenarios of energy policies, we investigated how the presence of an energy policy influences a duopoly firm's energy consumption. We found that oligopolies consider different energy policies and determine whether to take CSR by innovation. In accordance with Michelon [30], "it is necessary to clarify the complex relationship between CSR and firm performance". The CSR firm obtains a higher profit, compared to the common-product firm. Therefore, the society will gain a higher quantity of LEC products and a better environment. The energy tax rate changes in the same direction with the societal welfare, but opposite, with the consumer surplus. If a firm reduces energy consumption by an eco-R\&D, the tax cost will be decreased and it will have a long-term competitiveness, because of its recognition by the consumer. Noticeably, consumers prefer environment-friendly products. Additionally, the marginal cost of R\&D in low-energy techniques decreases and its production increases, while the marginal cost of the LEC products then also decrease, which means that corporations can turn this short-term financial pressure into a long-term investment.

Since the market was assumed to be fixed, in this paper, that is, it was beyond consideration that the market would shrink as a result of the levy of the energy tax and the price would increase. It is quite probable that the energy tax would cause a drastic increase in price, and the consumer would seek substitutions for such products, which would cause a lower profit and tax revenue. In particular, suppose that for the minimum level of environment CSR, for a firm eligible to receive a profit return, it is noteworthy that if a profit-seeking firm adopts the "do well by doing good" strategy, the firm has no incentive to undertake a level of CSR lower than the minimum, since it will not be recognized by consumers. On the other hand, a firm will not undertake a level of ECSR greater than the minimum, since its CSR effort beyond the minimum causes more cost without bringing the firm further benefits from the demand.

As topics for future research, we can explore the interactive impact of CSR and the firms' product market performance in this field, by means of CSR data from the Rankins Corporate Social Responsibility Ratings (RKS), which constructs a Social Responsibility Rating System, using a scoring algorithm of four dimensions: Macrocosm, Content, Technique and Industry. This system comprehensively dECSRibes the Chinese listed companies' CSR performance and disclosure, based on their CSR reports. Furthermore, due to the lack of variable settings and the unreasonable setting of parameter values, energy tax is only one of the many policy instruments and the behavior of other market structures has not been included, in this paper. It can be expanded in the future, such as the parameter design should be made more realistic, research on other market structures should be carried out. An investigation on how far this analysis also can be extended to oligopolistic markets, inside 
and out, that includes a competitive fringe, is suggested. Oligopolistic CSR markets, without an entry, could also be considered.

Author Contributions: The main contributions of A.C. are the theoretical model and literature review for this article. H.L. collected the data and empirical research to confirm the hypothesis in Section 3. Moreover, both authors discussed the intuitive explanation of the model, read and approved this version.

Funding: This research was funded by the National Natural Science Foundation of China under Grant 51707034, the Natural Science Foundation of Jiangsu Province under Grant BK20160679, and the National Social Science Foundation of China under Grant 15CJL039.

Acknowledgments: The authors would like to thank two anonymous referees for their valuable comments.

Conflicts of Interest: The authors declare that we have no conflicts of interest.

\section{References}

1. Isaksson, R.; Steimle, U. What does GRI Reporting tell us about Corporate Sustainability? TQM J. 2008, 21, 168-181. [CrossRef]

2. Wilson, M. Corporate Sustainability: What is it and where does it come from? Ivey Bus. J. 2003, 67, 1-5.

3. Song, M.L.; Zhang, W.; Wang, S.H. Inflection point of environmental Kuznets curve in Mainland China. Energy Policy 2013, 57, 14-20. [CrossRef]

4. Angela, C.; Wang, L.F.S. Industrial Policies and Partial Privatization in mixed oligopoly. J. Xi'an Jiaotong Univ. (Soc. Sci.) 2018, 38, 21-29. (In Chinese)

5. Bryane, M. Corporate social responsibility in international development: An overview and critique. Corp. Soc. Responsib. Environ. Manag. 2003, 10, 115-128.

6. Xu, S.K.; Yang, R.D. A conclusive analysis with in the conceptive scope of corporate social responsibility. China Ind. Econ. 2007, 5, 73-81. (In Chinese)

7. Friedman, M. The Social Responsibility of Business is to Increase Its Profits. N. Y. Times Mag. 1970, 32-33, 173-178.

8. Freeman, R.E. Strategic Management: A Stakeholder Approach; Cambridge University Press: Boston, MA, USA, 1984.

9. Carroll, A.B. A three-dimensional Conceptual Model of Corporate Social Performance. Acad. Manag. Rev. 1979, 4, 497-505. [CrossRef]

10. Carroll, A.B. The Pyramid of Corporate Social Responsibility: Toward the Moral Management of Organizational Stakeholders. Bus. Horiz. 1991, 34, 7-9. [CrossRef]

11. Wang, L.; Juslin, H. The effects of value on the perception of corporate social responsibility implementation: A study of Chinese Youth. Corp. Soc. Responsib. Environ. Manag. 2011, 18, 246-262. [CrossRef]

12. Wang, L.; Juslin, H. Values and corporate social responsibility perceptions of Chinese University Students. J. Acad. Ethics 2012, 10, 57-82. [CrossRef]

13. Porter, M.E.; Kramer, M.R. Strategy and Society: The Link between Competitive Advantage and Corporate Social Responsibility. Harv. Bus. Rev. 2006, 84, 78-92. [PubMed]

14. Liu, C.C.; Wang, L.F.S.; Lee, S.H. Strategic environmental corporate Social esponsibility in a differentiated duopoly market. Econ. Lett. 2015, 129, 108-111. [CrossRef]

15. Hirose, K.; Lee, S.H.; Matsumura, T. Environmental corporate social responsibility: A note on the first-mover advantage under price competition. Econ. Bull. 2017, 37, 214-221.

16. Abraham, L.; Zenu, S. Environmental corporate social responsibility and financial performance: Disentangling direct and indirect effects. Ecol. Econ. 2012, 78, 100-111.

17. Anderson, C.L.; Bieniaszewska, R.L. The role of corporate social responsibility in an oil company's expansion into new territories. Corp. Soc. Responsib. Environ. Manag. 2005, 12, 1-9. [CrossRef]

18. Weng, H.-H.; Chen, J.-S.; Chen, P.-C. Effects of Green Innovation on Environmental and Corporate Performance: A Stakeholder Perspective. Sustainability 2015, 7, 4997-5026. [CrossRef]

19. Li, Z. A study on relation of corporate social responsibility and corporate value-Empirical evidence from Shanghai Securities Exchange. China Ind. Econ 2006, 2, 77-83. (In Chinese)

20. Ohori, S. Price and Quantity competition in a mixed Duopoly with Emission Tax. Theor. Econ. Lett. 2014, 2, 133-138. [CrossRef] 
21. Wang, L.F.S.; Wang, J. Environmental Taxes in a Differentiated Mixed Duopoly. Econ. Syst. 2009, 33, 389-396. [CrossRef]

22. Angela, C.; Pu, Z. Corporate Social Responsibility and Environmentally Sound Technology in Endogenous Firm Growth. Sustainability 2017, 9. [CrossRef]

23. Manasakis, C.; Mitrokostas, E. Certification of Corporate Social Responsibility Activities in Oligopolistic Markets. Can. J. Econ. 2013, 46, 282-309. [CrossRef]

24. Manasakis, C.; Mitrokostas, E. Strategic Corporate Social Responsibility Activities and Corporate Governance in Imperfectly Competitive Markets. Manag. Decis. Econ. 2014, 35, 460-473. [CrossRef]

25. Song, M.; Zhang, W.; Wang, Z. Environmental efficiency and energy consumption of highway transportation systems in China. Int. J. Prod. Econ. 2016, 181, 441-449. [CrossRef]

26. Baron, D.P. Private Politics, Corporate Social Responsibility, and Integrated Strategy. J. Econ. Manag. Strateg. 2001, 10, 7-45. [CrossRef]

27. Baron, D.P. A Positive Theory of Moral Management, Social Pressure and Corporate Social Performance. J. Econ. Manag. Strateg. 2009, 18, 7-45. [CrossRef]

28. Bénabou, R.; Tirole, J. Individual and corporate social responsibility. Economica 2010, 77, 1-19. [CrossRef]

29. Lambertini, L.; Tampieri, A. On the Stability of MIxed Oligopoly Equilibria with CSR Firms. Tech. Rep. wp768. Dipartimento Scienze Economiche, Universita' di Bologna, 2011. Available online: http://ideas. repec.org/p/bol/bodewp/wp768.html (accessed on 16 September 2018).

30. Michelon, G.; Boesso, G.; Kumar, K. Examining the link between Strategic corporate social responsibility and company performance: An analysis of the best corporate citizens. Corp. Soc. Responsib. Environ. Manag. 2013, 20, 81-94. [CrossRef]

(C) 2018 by the authors. Licensee MDPI, Basel, Switzerland. This article is an open access article distributed under the terms and conditions of the Creative Commons Attribution (CC BY) license (http:/ / creativecommons.org/licenses/by/4.0/). 